\title{
Gain Scheduling Analysis of Conventional Controller for Output Voltage Control of Distributed Generation Voltage Source Inverter-DGVSI by Different Methods
}

\author{
Nalini Karchi', Deepak Kulkarni ${ }^{2}$ and Sujata Patil ${ }^{3}$ \\ ${ }^{1}$ Department of Electrical and Electronics, KLE Dr M S Sheshgiri College of Engineering, Belagavi India, \\ ${ }^{2}$ Department of Electrical and Electronics Engineering, KLE Gogte Institute of Technology, Belagavi, India \\ ${ }^{3}$ Department of Electrical and Electronics, KLE Dr M S Sheshgiri College of Engineering, Belagavi India,
}

\begin{abstract}
The local voltage control in Distribution Generation (DG) is most important task. The proportional - Integral (PI) controller is used to control the voltage of three phase inverter in Distributed Generation System. The system is expressed on $d-q$ frame transformation for MATLAB-simulink. The proposed work is to analysis Distributed Generation Voltage Source Inverter-DGVSI in time and frequency domain. The gain of standalone solar inverter conventional controller is determined by Ziegler Nichol's, filter parameter time constant and PID tuner in MATLAB. The analysis is done with the help of results found by step response, frequency response and output voltage waveform. The studied system is modeled, simulated and analyzed in MATLAB-SIMULINK environment.
\end{abstract}

\section{KEY WORDS: CONTROLLER, DISTRIBUTION GENERATION, RENEWABLE ENERGY SOURCES, POWER ELECTRONICS.}

\section{INTRODUCTION}

The power system consists of conventional and non conventional generating units. In modern power system, the role of power electronics components and distributed generation is well understood. There are many advantages of connecting distributed generation to power grid. The connection of distributed generation to power grid is through electronics devices. 'Distributed generation' is either permanently or timely present with power grid (Puttamadappa, C. et al 2019). As they are not actively participating all the time, may incorporate the technical challenges in the power grid. Before the connection

\section{ARTICLE INFORMATION}

*Corresponding Author: nnnalini2000@rediff.com

Received 8th Oct 2020 Accepted after revision 27th Dec 2020

Print ISSN: 0974-6455 Online ISSN: 2321-4007 CODEN: BBRCBA

Thomson Reuters ISI Web of Science Clarivate Analytics USA and Crossref Indexed Journal

\section{Clarivate
Analytics}

NAAS Journal Score 2020 (4.31)

A Society of Science and Nature Publication,

Bhopal India 2020. All rights reserved.

Online Contents Available at: http//www.bbrc.in/

Doi: http://dx.doi.org/10.21786/bbrc/13.13/14 of 'DG' to the grid, the local voltage of 'Distributed generation-DG' has to be maintained according to the standards. Many factors are affecting on the output of DG.

The output of DG is influenced by the type of load and its nature. The voltage of DG has to be maintained constant irrespective all loads. It is very necessary that some extra controlling devices are required to control the DG output. To maintain the power quality, many system parameters are required to be monitored and controlled. The local voltage control of DG is also the essential parameter which to be controlled. As the 'distributed generation' is interacted to the power grid through power electronic devices, the control of output voltage has become easy. The output of power electronics circuit is controlled by using the traditional PI controller. In the paper the controller constants are determined by traditional methods (Math HJ, 2018).

The renewable energy based electrical generation units are located at the distribution network. So they are called as distributed generation (fig 1). They are small

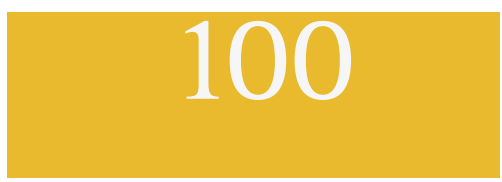


scale power generation units. Their capacity ranges from $10 \mathrm{KW}$ to $20 \mathrm{MW}$. They are placed very close to end user. The transmission losses are reduced due to short distance between generation and consumption point. They can be operated in grid connected and standalone mode. The connection operation is feasible due to power electronic and FACTs interfacing devices. The independent operation of Solar Inverter is referred as Standalone or island distributed generating unit. The input to grid connected inverter is DC output from the solar plant, wind plant etc.

The dc input is maintained by dc converter and dc link system. The aim of grid connected inverter is control the power flow to the grid; stabilize output voltage along with constant frequency. The inverter supplies the power with less harmonic distortion. The filter is used to maintain the shape of sinusoidal voltage and current and reduce the higher order frequency components. These filters work high switching frequency to attenuate high frequency harmonics in grid. The grid is sensitive to load variations. The load variations will cause to increase in reactive power, harmonics distortion, rush in current (Math HJ 2018). The grid side inverters are designed with PWM technology. These inverters provide the flexibility in controlling the voltage harmonics and power flow within the limit.

Figure 1: Block diagram of distributed generation

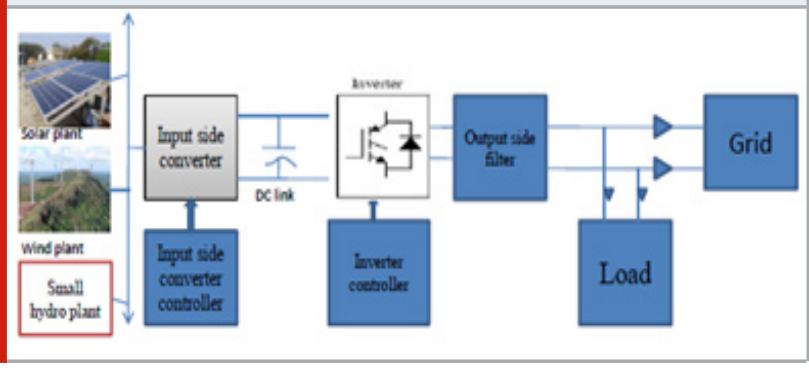

The control design for the three phase inverters involves main two steps; open loop control and dynamic closed loop control. The proper shaped sinusoidal output voltage with constant magnitude, less harmonic distortion is one of key issues to deal the distributed generation system. To maintain the output of PWM inverter as per IEEE standards, many control schemes are used for grid connected PWM inverters. The PID control strategy is widely selected to control the above parameters control in grid connected inverters. The controllers are implemented in the feedback path of inverters. The role of controller is based upon their location in Distribution generation system. They are MPPT controller, DC link controller, Voltage and current controller of PWM inverter, FACTS controller etc. The gain tuning of PID controller is difficult task. The gains of controllers are determined by manually, numerical method, AI algorithms.

\section{MATERIAL AND METHODS}

Modeling Of 3- $\theta$ Solar Inverter- DGVSI System: The survey is done at SURYODAYA ENERGY ONE PVL.LTD at Gokak and $430 \mathrm{kWp}$ Solar PV plant at KLS Gogte Institute of technology, Belagavi. The capacity of Gokak plant is $40 \mathrm{MW}$. The total Land occupied by plant is 180 Acres. This survey is done to collect the real time data and understand the solar generation system.

Solar Array Capacity: Karnataka has sufficient solar energy access. In a year, 240 to 300 days are sunny days with solar radiations of 4 to $7 \mathrm{KWh} / \mathrm{m} 2 / \mathrm{d}$ ay. The capacity of the solar modules array of a proposed solar PV system is calculated with the following steps. Karnataka Electric Regulatory Commission- KERC, the electricity act 2003 has given the guidelines to fix the capacity of solar panel. If the annual energy consumption is $15000 \mathrm{kWh}$, then the average annual energy generation per installed kW of solar PV capacity is $1500 \mathrm{kWh}$ (this number assumes a system capacity utilization factor of $18 \%$ and average grid availability of 95\% during the day time). The determined annual solar capacity is $9 \mathrm{kWh}$. The recommended capacity of PV panel is selected as 10kWh (Ioan Viorel Banu, 2012).

Solar Inverter Capacity: Karnataka Electric Regulatory Commission -KERC for solar plant has recommended 'solar inverter capacity' in kW. It should be in the range of 95\% to $110 \%$ of the solar PV array capacity. In above paragraph the solar array capacity is $10 \mathrm{kWh}$. Therefore the required inverter rating for this array would be 10 to $11 \mathrm{~kW}$. The selected inverter is PWM inverter; it has to be supplied by more power from PV panel. The considered modulation index is 0.5 .Therefore the maximum input voltage to the inverter is expected to 800 to 1000 Volts by the relation (1) ( Somera).

Three Phase Inverter Voltage: The voltage source inverters are used for energy conversion from a dc source to an AC output. The three phase, two-level converter (IGBT) with a LC filter at each phase. Let, Vdc is the inverter input DC voltage and Vs is the inverter output $\mathrm{AC}$ voltage. The maximum amplitude of the fundamental phase voltage in the linear region is $\mathrm{V}_{\mathrm{dc}}{ }^{2}$, the maximum amplitude of the fundamental ac output line voltage is $\operatorname{sqrt}(3)^{*} \mathrm{~V}_{\mathrm{dc}}{ }^{2}$ (Muhammad H Rashid.. 2018). The relation between these two voltages from power electronics theory is given below, where $m=$ modulation index $(m=1)$ et.al (Umanand L, Bandana Bhutia, Sihem Elhelali)

$$
V_{s}=m \frac{\sqrt{3}}{2} V_{a c}
$$

The Laplace transform of (1) is given by (2)

$$
\frac{V_{s}(s)}{V_{d k}(s)}=m \frac{\sqrt{3}}{2}
$$


The $d-q$ frame transform technique is used to measure the actual output voltage of three phase distributed generation inverter. The DC equivalent of three phase ac voltage is found by $\alpha-\beta$ transformation technique. The actual voltage in the form of dc voltage is taken as feedback to controller. The instantaneous three phase voltages are transformed in a fixed two-axis $(\alpha-\beta)$ coordinate system as (3) et.al (Umanand L, Ioannis C).

$$
\left[\begin{array}{l}
v_{\alpha} \\
v_{\beta}
\end{array}\right]=\sqrt{\frac{2}{3}}\left[\begin{array}{ccc}
1 & -\frac{1}{2} & -\frac{1}{2} \\
0 & \frac{\sqrt{3}}{2} & \frac{-\sqrt{3}}{2}
\end{array}\right]\left[\begin{array}{l}
v_{a} \\
v_{b} \\
v_{c}
\end{array}\right]
$$

Where $\mathrm{V}_{\mathrm{a}}, \mathrm{V}_{\mathrm{b}}$ and $\mathrm{V}_{\mathrm{c}}$ are three phase voltages. The voltage vector is obtained by the above transformation formula. It is further transformed into a rotating $\mathrm{d}-\mathrm{q}$ frame coordinate using the following equation (4)

$$
v_{d}+j v_{q}=e^{-j \theta}\left(v_{\alpha}+j v_{\beta}\right)
$$

Direct axis voltage is $V_{d}$ and Quadratic axis voltage is $\mathrm{V}_{\mathrm{q}} \cdot \theta$ is the transformation angle calculated for the initial value of $\theta_{0}$ as shown in the equation (5)

$$
\theta=\theta_{0}+\int_{0}^{t} \omega(t) d t
$$

\section{Design of Lc Filter}

Inductance of Lc Filter - LF: The output voltage waveform is synchronized with the grid voltage so the PWM inverter will inject ripple current in load or grid. The LC filter is selected to remove high switching frequency components from output current of inverter. The RMS value of line voltage, Phase voltage, Rated active power, DC input voltage of Inverter, Grid frequency, Switching frequency, resonance frequency are the factors need to be considered in designing a LC filter. The value of inductance-Lf is determined by taking the percentage value of ripple current. This current can be selected as 10\%-15\% of rated current. The value of inductor Lf of filter in this system is obtained by (6) (Reznik, A 2012).

$$
L_{f}=0.1 I_{\max }=\frac{0.1 *(\text { linevoltage })^{2}}{2 * \text { pi*f*rated } \ldots \text { power }}
$$

The Capacitance-Cf: The capacitor- Cf of LC filter is designed based on reactive power supplied by the capacitor at fundamental frequency- $\mathrm{f}(\mathrm{Hz})$. It is considered that the maximum power factor variation seen by the grid is $5 \%$ is used (Sihem Elhelali, 2013).

$$
C_{f}=\frac{0.05 * \text { rated ...power }}{2 * \text { pi*f*(linevoltage })^{2}}
$$

Determine the series resistance of inductance, $R_{f}$ by the relation (8)

$$
R_{f}=100 * L_{f}
$$

The values are assigned to the filter components. One line diagram of the filter is shown in (Fig 3)

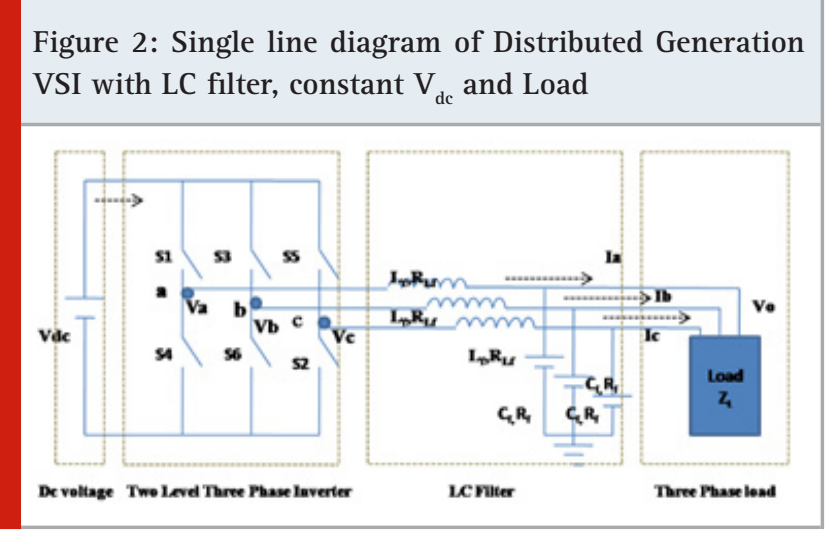

Figure 3: The equivalent diagram of inverter and LC filter

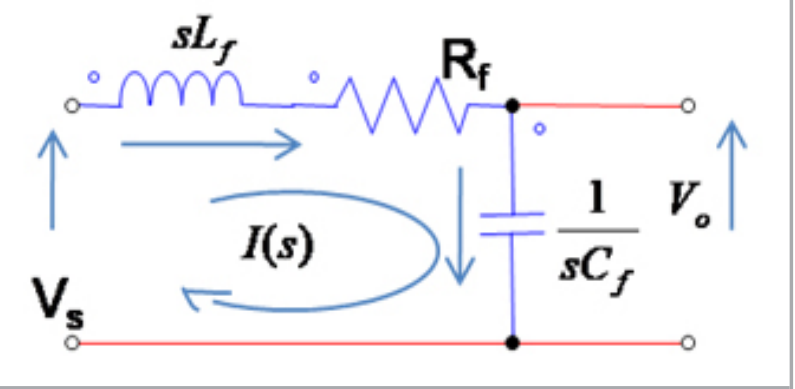

The Proportional - Integral (PI) Controller

There are many controllers functioning in the power grid. The most famous and simple

controller is PI controller. The mathematical equation of PI controller is given by (9)

$$
u(t)=k_{p} e(t)+k_{i} \int e(t) d t
$$

Where $\mathrm{k}_{\mathrm{p}}=$ proportional gain, $\mathrm{k}_{\mathrm{i}}=$ Integral gain, $\mathrm{e}(\mathrm{t})=$ error signal, $\mathrm{u}(\mathrm{t})$ is output signal of controller.

The Overall Transfer Function Of The Dgvsi - System Refer (fig 4), the transfer function is obtained by assuming ground to neutral voltage, $\mathrm{V}_{\mathrm{gn}}=\left(\mathrm{V}_{\mathrm{an}}+\mathrm{V}_{\mathrm{bn}}+\mathrm{V}_{\mathrm{cn}}\right) / 3$ at zero. Here $V_{a n}, V_{b n}$, and $V_{c n}$ are each phase neutral voltage respectively. Consider the loop I node a-b-N-a and apply the KVL (Shahab Shahid Khawaja 2015),

$$
V_{s}=\left(s L_{f}+R_{l f}\right) I_{f}+\left(R_{c f}+\frac{1}{s C_{f}}\right) I_{c}
$$

The current relation is found by applying KCL at node $\mathrm{b}$, 
where $I_{c}=I_{f}+I_{L}$

Applying the KVL to the loop b-N-b,

$$
\begin{aligned}
& \left(R_{c f}+\frac{1}{s C_{f}}\right) I_{o}=I_{L} Z_{L} \\
& V_{o}=I_{L} Z_{L}
\end{aligned}
$$

Combining (10),(11),(12),(13), we get the function

$$
V_{s}=\frac{\left(s^{2} L_{f} C_{f}+s C_{f}\left(R_{L f}+R_{C f}\right)+1\right)}{s R_{C f} C_{f}+1} V_{0}+\left(s L_{f}+R_{L f}\right) I_{L}
$$

Therefore the simplified function is found by (15)

$$
V_{s}=\left(\frac{\left(s^{2} L_{f} C_{f}+s C_{f}\left(R_{L f}+R_{C f}\right)+1\right)}{s R_{C f} C_{f}+1}+\frac{\left(s L_{f}+R_{L f}\right)}{Z_{L}}\right) Y_{0}
$$

The overall transfer function with load $\mathrm{V}_{\mathrm{s}} / \mathrm{V}_{\mathrm{o}}$,

At no load the system function (18) is modified form by substituting IL in (16)

$$
\begin{aligned}
& T \cdot F=\frac{1}{\left(\frac{\left(s^{2} L_{f} C_{f}+s C_{f}\left(R_{L_{f f}}+R_{C f}\right)+1\right)}{s R_{C f} C_{f}+1}+\frac{\left(s L_{f}+R_{L f}\right)}{Z_{L}}\right)} \\
& I_{L}=0
\end{aligned}
$$

The transfer function is found for fixed $V_{d c}$. By substituting $\mathrm{V}_{\mathrm{s}}=\mathrm{m} . \mathrm{k} . \mathrm{V}_{\mathrm{dc}}$.It is given by (19)

$$
G=T \cdot F_{s}=V_{d c} \frac{s R_{C f} C_{f}+1}{s^{2} L_{f} C_{f}+s C_{f}\left(R_{L f}+R_{C f}\right)+1}
$$

Figure 4: The Single Phase Equivalent of a 3-phase twolevel DGVSI with LC filter and output voltage

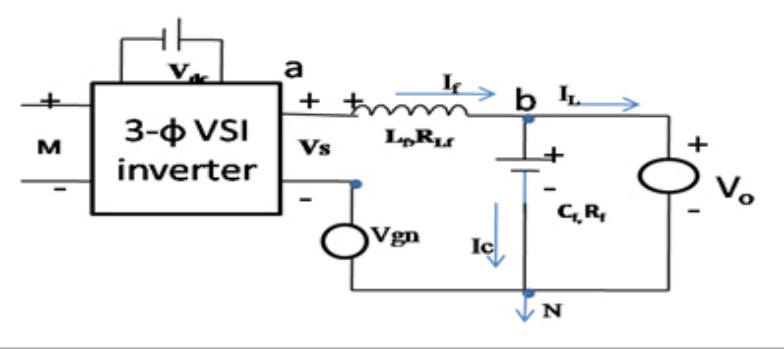

The proposed system is tested for the following system specifications

the system's function after substituting the values of parameters is given in (16)
Table 1. Specifications of the inverter and LC filter

\begin{tabular}{|l|c|c|}
\hline Terms & Value & Abbreviation \\
\hline Minimum active power & $5 \mathrm{e} 3 \mathrm{watt}$ & Pmin \\
\hline Maximum active power & $10 \mathrm{e} \mathrm{W}$ & Pmax \\
\hline $\begin{array}{l}\text { Inverter phase2phase } \\
\text { voltage }\end{array}$ & $380 \mathrm{Volt}$ & $\mathrm{U}$ \\
\hline Frequency & $50 \mathrm{~Hz}$ & $\mathrm{~F}$ \\
\hline Switching frequency & $10 \mathrm{e} 3$ & $\mathrm{fsw}$ \\
\hline Filter capacitor at Pmin & $5.5 \mathrm{uF}$ & Cfmin \\
\hline Filter capacitor at Pmax & $1.1022 \mathrm{e}-05$ & Cfmax \\
\hline Filer Inductance at Pmin & $9.2 \mathrm{mH}$ & Lf \\
\hline Filer Inductance at Pmax & $0.0046 \mathrm{H}$ & Lfmax \\
\hline Resistance of Inductor & $\begin{array}{l}0.919278951 \\
298788 \mathrm{ohm}\end{array}$ & RLf \\
& & \\
\hline
\end{tabular}

$$
T . F=\frac{1.102 \mathrm{e}-08 \mathrm{~s}+1}{1.013 \mathrm{e}-07 \mathrm{~s}^{2}+1.014 e-05 \mathrm{~s}+1}
$$

The controller transfer function is given by the relation (21)

$$
C=T \cdot F_{c}=K_{p}+\frac{K_{i}}{\mathrm{~s}}
$$

Controller Parameter Design: The controller transfer function is given by the relation shown in (21).The controller parameters are determined by applying following methods,

Ziegler And Nicholas Method -ZN: This is basic tuning method to set the values of controller $\mathrm{K}_{\mathrm{p}}$ and $\mathrm{K}_{\mathrm{i}}$. They are determined by using the formula $\mathrm{K}_{\mathrm{p}}=0.9 \mathrm{~T} / \mathrm{L}$ and $\mathrm{K}_{\mathrm{i}}=\mathrm{K}_{\mathrm{p}} /$ $\mathrm{T}_{\mathrm{i}}$. The $\mathrm{T}$ and $\mathrm{L}$ values are found from Step response of open loop system. Where $\mathrm{a}=\mathrm{L} / \mathrm{T}, \mathrm{T}_{\mathrm{i}}=\mathrm{L} / 0.3, \mathrm{~L}=$ dead time and $\mathrm{T}=$ time constant (Nagrath I J.2017).

PID Tuner In Matlab: This app is available in MATLAB software. This is used to determine the controller function and gains. The selected gain values by PID tuner are from rise time and slow time. They have not been taken directly as given by PID tuner.

Figure 5: The Controller gain by PID tuner in MATLAB

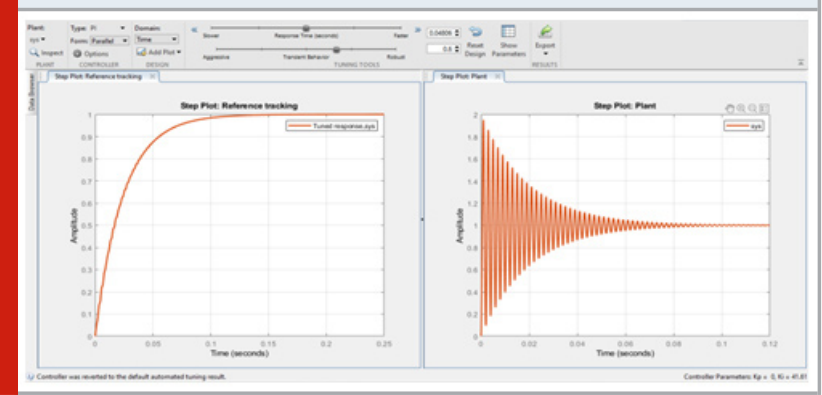


Using Filter Capacitance And Inductance Values

The controller's constants are determined as given in (23) and (24)

Value of $K_{p}=\frac{\text { Capaci } \tan c e}{\text { time constant }}$

Value of $K_{i}=\frac{\text { inductan } c e}{\text { time constant }}$

The overall closed loop Transfer function (25)

Closed loop $T \cdot F=\frac{G C}{1+G C}$

The determined controller gains are shown in the (table 2)

Table 2. Controller gains found by three methods

\begin{tabular}{|l|c|c|c|}
\hline Parameters & $\begin{array}{c}\text { Ziegler and } \\
\text { Nicholas Method }\end{array}$ & $\begin{array}{c}\text { PID tuner } \\
\text { in MATLAB }\end{array}$ & $\begin{array}{c}\text { Filter capacitance and } \\
\text { inductance values }\end{array}$ \\
\hline $\mathrm{Kp}$ & 0.0026 & $1.5382 \mathrm{e}-07$ & 0.5 \\
\hline $\mathrm{Ki}$ & 4.5680 & 0.0640 & 0.001 \\
\hline
\end{tabular}

Transient And Frequency Analysis of the System: The transient response and frequency response of open loop system is found on MATLAB platform. The step response is shown in (fig 6). Bode method is applied to get magnitude and phase plot of open loop DGVSI (fig 6). The results are shown in (table 3).

Figure 6: The step response and frequency response of the open loop DGVSI system
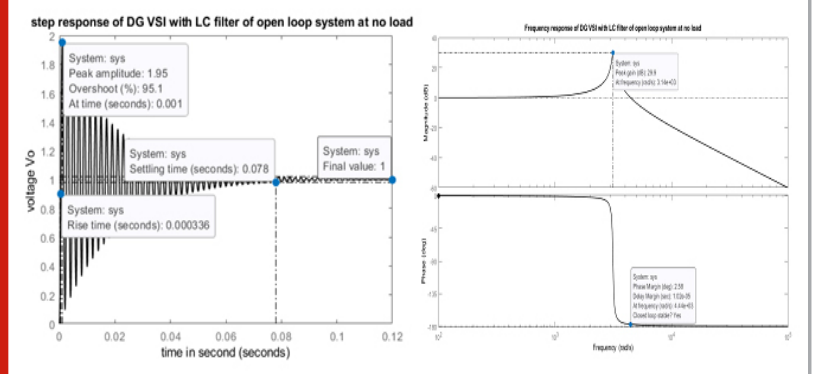

Figure 8: The frequency response of the closed loop DGVSI System fig(d)-Ziegler-Nicholas fig(e)-PID tuner, fig(f)Filter parameter time constant
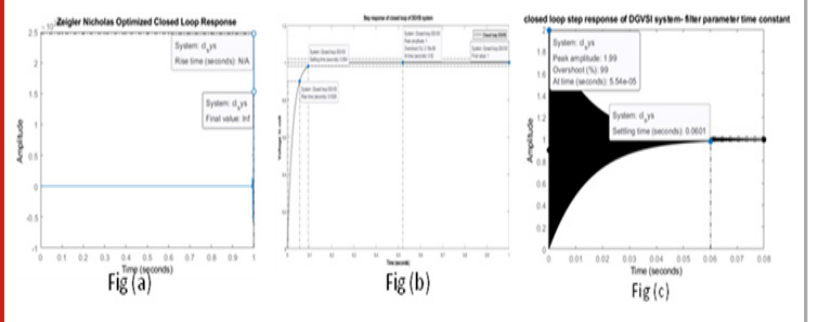

\section{RESULT AND ANALYSIS}

The system is modeled and simulated on MATLAB platform. The open loop transient response experiences the oscillations with peak overshoot of 95.1 percent. The

Figure 9: The output line voltage waveforms of the closed loop DGVSI System fig(g)-Ziegler Nicholas fig(h)-PID tuner, fig(i)-Filter Parameter Time Constant.
Fig(g)

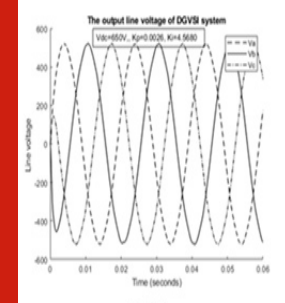

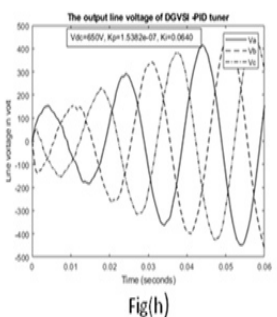

fig $(h)$

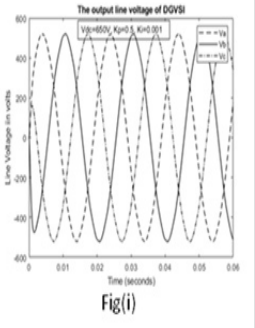

Figure 10: The FFT analysis of output line voltage of DGVSI system

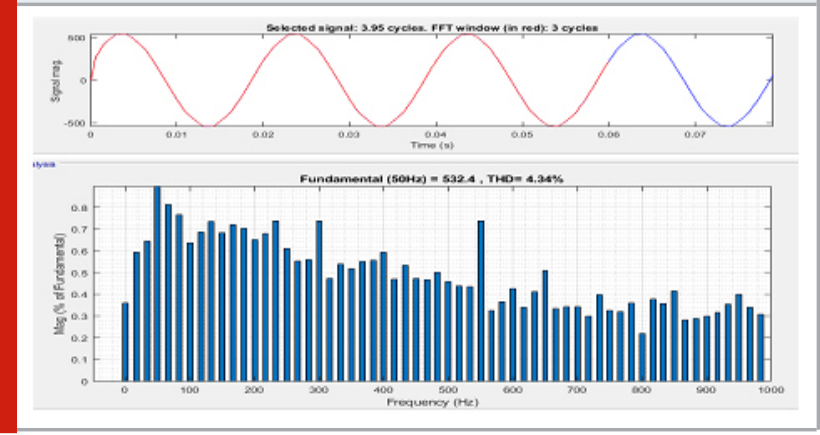

settling time is 0.078 seconds. The resonant frequency is $3.14 \mathrm{e} 03 \mathrm{rad} / \mathrm{sec}(50 \mathrm{~Hz})$ (fig $6 \mathrm{~b})$. The controller gains are obtained by three methods. The modeled system is tested with fixed dc input voltage to the DGVSI. It is functioning properly. The time and frequency domain results of closed loop system by three methods are compared. The Step response of closed loop system by three methods is shown in (fig 7). The frequency response of closed loop DGVSI is graphed in (fig 8). Ref (Fig 9), the shape of output line voltage waveform of DGVSI is observed sinusoidal in nature. 
Table 3. Transient and Frequency analysis result of open loop system

\begin{tabular}{|l|c|c|c|}
\hline \multicolumn{2}{|l|}{ Step Response analysis } & \multicolumn{2}{c|}{ Frequency Domain Analysis } \\
\hline Peak Overshoot in Percentage & 95.1 & Peak gain in dB & 29.9 \\
\hline Rise time in second & 0.000336 & Resonant frequency in rad/sec & $3.14 \mathrm{e}+03$ \\
\hline Settling time in second & 0.078 & Phase margin (degree) & 2.58 \\
\hline
\end{tabular}

Table 4. Transient and frequency analysis result of closed loop system

\begin{tabular}{|l|c|c|c|}
\hline Terms & $\begin{array}{c}\text { Ziegler- } \\
\text { Nicholas }\end{array}$ & $\begin{array}{c}\text { PID } \\
\text { tuner }\end{array}$ & $\begin{array}{c}\text { Filter parameter } \\
\text { time constant }\end{array}$ \\
\hline Peak overshoot in percentage & Inf & 0 & 99.1 \\
\hline Settling time in second & NA & 0.094 & 0.062 \\
\hline Peak gain in dB & 10.9 & 2.96 & 52.2 \\
\hline Resonant frequency in rad /sec & $5.23 e+03$ & $3.14 \mathrm{e}+03$ & $5.67 \mathrm{e}+04$ \\
\hline
\end{tabular}

Among the three methods, the gain obtained by PID tuner is more stable. The transient response and frequency response both are steady and stable. The settling time increases by PID tuner method and system response becomes sluggish as shown in (fig 7 (b)). Ref (fig 7 (b)), the oscillations are completely damped out which are observed in step response of open loop DGVSI system. By PID tuner method, the resonant frequency is not changed. The gain margin is also improved (fig 8(e)). The other two graphs (fig 7 (a) and fig 7 (c)) are faster than (fig 7 (b)). The same is reflected in the line voltage waveform where voltage is reached its final value quickly (fig 9 (g) and fig 9 (i)). The speed of response of closed loop system due to Ziegler-Nicholas (ZN) and Filter parameter time constant is fast.

The system do not remain in stable state as shown in (fig 7 (a)). The time response due to filter parameter time constant exhibits more oscillations. The peak overshoot is increased from 95.1 to 99.1 (fig 7(c)). The settling time is also reduced as shown in (fig 7(c)). Ref (fig 8), (fig 8 (b)) shows stable gain margin and phase margin due to PID tuner method (table 4). The percentage of harmonics is observed by FFT analysis. The value of harmonics content in line voltage is $4.43 \%$ which is less than 5 $\%$ (fig. 10).

Future Scope: The controller parameter can be found by various methods to stabilize the system. The controller gain will be adapted by implementing the artificial intelligence algorithm. The results show that gain of controller determined by PID tuner in MATLAB is more suitable. The closed loop system is more stable. ZieglerNicholas method is primary method to set the gain of controller. Filter parameter time constant is applicable only this system where LC Filter has been used. There are other ways to obtain gain like neural network, fuzzy logic and artificial intelligent soft algorithms etc. The system becomes more complex due to nonlinearity characteristics of this algorithm. The guarantee of convergence is less with this soft algorithm. The PID tuner is fast and simple to obtain the gain of controller.

\section{CONCLUSION}

The results show that gain of controller determined by PID tuner in MATLAB is more accurate. The closed loop system is more stable. Ziegler-Nicholas method is primary method to set the gain of controller. Filter parameter time constant is applicable only this system where LC Filter has been used. There are other ways to obtain gain like neural network, fuzzy logic and artificial intelligent soft algorithms etc. The system becomes more complex due to nonlinearity characteristics of this algorithm. The guarantee of convergence is less with this soft algorithm. The PID tuner is fast and simple to obtain the gain of controller. The resonant frequency of system if maintained same by PID tuner while finding the gains.

Findings: From the analysis of above result, it is found that all above methods of gain scheduling of controller need the time. These all are first level methods. The gain of controller is adjusted manually. For the real time system, the gain has to be adapted according to the change in output voltage of inverter. Existing comparison suggests, the use of artificial algorithm for controller tuning to improve the flexibility and adaption according to change in the output voltage of DGVSI. The gain values can be used as base values for research work. Time and frequency analysis can be used for selection of gain values as well as comparison purpose in the research work (Nalini Karchi 2016). 
Conflict of Interest: No conflict of interest

\section{REFERENCE}

Bandana Bhutia, Dr. Ali S.M., Narayan Tiad, (2014). Design of Three Phase PWM Voltage Source Inverter For Photovoltaic Application. International Journal Of Innovative Research in Electrical and Electronics. INSTRUMENTATION AND CONTROL ENGINEERING Vol. 2. Issue 4. ISSN (Online) 2321 - 2004 ISSN (Print) 2321 - 5526.

Ioan Viorel Banu, (2012). Modeling and simulation of photovoltaic arrays. worlf Energy System ConferenceWESC.

Ioannis C. Konstantakopoulos, Michael K. Bourdoulis, (2012). An Alternative PI controller design approach for PWM regulated ac/dc three phase converters. IEEE International Conference on Industrial Technology (ICIT). Athens. Greece.

Math H.J. Bollen, Fainan Hassan (2018). Integration of Distributed Generation in the Power System. Wiley. ISBN:978-81-265-7326-4

Muhammad H Rashid. (2018) Power Electronics: Devices, circuits and Applications. Pearson India Education Services Pvt. Ltd. ISBN 978-93-325-8458-7

Nagrath I, J., M.Gopal (2014). Control System Engineering. New Age International (P) Ltd. ISBN:97881-224-2008-1

Nalini Karchi, D. B. Kulkarni. (2016). Review of control of power oscillations in integrated distributed generation and control techniques. International
Journal of Technology and Science 3 (Issue 2), 54-59. Puttamadappa, C., and B. D. Parameshachari. "Demand side management of small scale loads in a smart grid using glow-worm swarm optimization technique." Microprocessors and Microsystems 71 (2019): 102886. Reznik, A., M. Godoy Simoes, Ahmed Al-Durra, and S. M. Muyeen. (2012). LCL filter design and performance analysis for small wind turbine systems. IEEE Power Electronics and Machines in Wind Applications.

Shahab Shahid Khawaja, Mohsin Jamil, Qasim Awais, Umer Asgher and Yasar Ayaz (2015). Analysis of Classical Controller by Variation of Inner loop and ControllerGain for Two level Grid connected Converter. Indian Journal of Science and Technology. Vol 8 (20). DOI: 10.17485/ijst/2015/v8i20/78481.ISSN(print):09746846.ISSN(online):0974-5645.

Sihem Elhelali, Noureddine Hidouri, Lassaad Sbita. (2013). A controlled topology for a grid connected photovoltaic system. International Conference on Control Engineering and Information Technology.Vol 3.pp 33-38

Somera -High efficiency mono Si PV Modules -Vikramsolar

Umanand L, (2010). Power Electronics: Essentials and Applications. Wiley India Pvt. Ltd. ISBN:978-81-2651945-3

Xinya Song, Teng Jiang, Steffen Schlegel, Dirk Westermann, (2019). Parameter Tuning for dynamic Digital Twins in Inverter-Dominated Distribution Grid,October,IET Renewable Power Generation 14(2),DOI: 10.1049/iet-rpg.2019.0163 